East African Medical Journal Vol. 78 No. 6 June 2001

HEALTH SERVICES UTILISATION AMONG SECONDARY SCHOOL STUDENTS IN ARUSHA REGION, TANZANIA

M. C. Masatu, MD, MSc, PhD student, Centre for International Health, Faculty of Medicine, University of Bergen, Norway, W. L. Lugoe, MD. PhD, MA, MSc, PhD, Senior Lecturer, Department of Educational Psychology, University of Dar es Salaam, P.O. Box 35048, Dar es Salaam, Tanzania, G. Kvåle, B. Ed, Professor, Centre for International Health, Faculty of Medicine, University of Bergen, N-5021 Bergen, Norway and K-I. Klepp, PhD, MPH, Professor, Institute for Nutrition Research, University of Oslo, Postboks 1046 Blindern, 0316 Oslo, Norway.

Request for reprints to: Dr. M. C. Masatu, Centre for International Health, University of Bergen, Armauer Hansen Building, N-5021 Bergen, Norway.

\title{
HEALTH SERVICES UTILISATION AMONG SECONDARY SCHOOL STUDENTS IN ARUSHA REGION, TANZANIA
}

\author{
M. C. MASATU, W. L. LUGOE, G. KVÅLE and K-I. KLEPP
}

\begin{abstract}
Objective: To investigate patterns and determinants of health services utilisation by secondary school students.

Design: A cross-sectional survey.

Setting: Twelve secondary schools located within seven districts of Arusha region Tanzania. Participants: Three thousand six hundred and three students proportionately selected from the twelve schools according to enrolment size.

Main outcome measures: Self-reported use of modern and traditional health services within the past two years.

Results: The majority (77\%) of the students used only modern health services while very few $(1.3 \%)$ used only traditional services. Fever was the main reason for seeking health care during the last visit. Respondents who used traditional services expressed lower level of satisfaction with the services than those who used modern services. Living situation and socio-economic status of respondent's family predicted utilisation of modern health services whereas self-rated health status and perception that poverty was a threat against one's health predicted utilisation of traditional health services.

Conclusions: Since most of secondary school students use modern health services, improvement of the modern health system is likely to benefit this population. Further work is needed to elucidate factors that facilitate or impede use of heal th services by young people in Tanzania.
\end{abstract}

\section{INTRODUCTION}

In Tanzania, modern health services are being provided largely by government-owned facilities (hospitals, health centres and dispensaries) and supplemented by privatefor-profit and non-profit voluntary agencies. Attendance to a fixed health care delivery facility is required, since limited out-reach services exist. Nationwide, and also in the Arusha region, it is estimated that there are two health facilities per 10, 000 people(1). In 1993, user fee was introduced for services in government-owned hospitals except for pregnant women, children aged five years or below, people with chronic illnesses such as tuberculosis and leprosy and those who can not afford to pay(2). According to current policy, health services in governmentowned health centres and dispensaries ought to be free of charge. Private health insurance system is underdeveloped. Traditional health services also exist and are being provided by a wide range of healers including herbalists, spiritual (faith) healers, diviners, circumcision practitioners and traditional birth attendants $(3,4)$.

Formal education in Tanzania begins with primary school at age 7. Primary education lasts for seven years and is followed by six years of secondary education, which qualifies for college or University level. Less than a fifth of the primary school leavers go on to secondary school.

A study conducted recently among primary school pupils in Tanzania found that the majority $(85 \%)$ of respondents used modern health services, fever being the main reason for seeking health care, and that the respondents by-and-large were satisfied with the services they received(5). Secondary school students represent a selected and well-educated group of young people. In addition, secondary school students are older than primary school pupils and thus they may have different types of health complaints. Also, they are expected to have developed greater autonomy with regard to making important decisions including the use of health services. Hence, their pattern of health services utilisation may be different from that of primary school pupils. However, little is known about how secondary school students utilise available health services and the determinants of health services utilisation.

Identification of factors that facilitate or impede effective use of health services by young people may help to identify those who may be particularly disadvantaged, and hence provide information that policy makers can use to target services to those in greatest need 
A Health Behaviour Model proposed by Aday and Anderson(6) has been widely used in the study of health services utilisation. In this model health services utilisation is seen to be the result of characteristics of the population (predisposing, enabling, need) and characteristics of the health care system (health policy, resources, organisation). Predisposing factors are those existing prior to disease, including age, sex, family composition, and health carerelated beliefs and attitudes. Enabling factors refer to conditions that affect one's ability to access the health care system, such as family income, health insurance, availability of regular source of care and physical accessibility to the health facilities. Need factors are the most proximal and immediate cause of health service utilisation. They include burden of illness as perceived by the individual (self-rated health status) and objective assessment by experts.

Several researchers have used the population characteristics in examining determinants of modern health services utilisation among adults(7-10), adolescents(11) and children(12). Also, some investigators have adapted the Health Behaviour Model to explain utilisation of other forms of health services such as traditional healers and informal drug sellers $(13,14)$. Ryan and colleagues, in their study of adolescents in the United States of America, found that having a regular source of care and insurance (enabling factors) were strong predictors of routine use of medical and dental services, whereas having a physical health problem (need factor) and socio-demographic factors (predisposing) were more important in predicting illnessrelated care (11).

The purpose of this study was to investigate patterns and determinants of health services use by secondary school students, using the population characteristics in the Health Behaviour Model by Aday and Andersen as a guide.

\section{MATERIALS AND METHODS}

Population and sampling: Participants were sampled from 12 of the 50 secondary schools in the Arusha region, Tanzania. The twelve schools were part of the on-going project "Counselling, education and heal th promotion (CEHP) in telation to HIV/AIDS". Schools were selected based on a range of characteristics: location (urban, semi-urban, rural); size (at least an enrolment of 250 students); religious affiliation (seminary, non-seminary), gender composition (girls only, boys only, mixed) and residential status (boarding, day only). The twelve schools were located within seven of the ten districts of the Arusha region and the total enrolment in these schools was approximately 7000 .

A sample of 3926 students was selected proportionately from the 12 schools. In each school, systematic sampling technique was used to select participants within each grade, stratified by gender, except the 12th grade (form four). Form four students were excluded since they would not be available for a planned follow-up study.

All selected students were invited to participate in the study. In total, 3603 out of the invited 3926 students participated, participation rate being; $91.8 \%$. Non-participants were absent at school on the day of data collection and they were neither replaced nor re-contacted. Of the participants, 1859 were males, 1726 were females and 18 did not specify their gender. Over half $(55.3 \%)$ of the males were aged 18 years or more while the corresponding proportion for females was $28.6 \%$.

Procedure: Research clearance was obtained from the Tanzanian Ministry of Education and Culture, and education authorities for Arusha region and the seven districts in which the schools were located. In addition, permission from heads of the schools and an informed verbal consent from students were obtained before data collection. Participants were advised that participation in the study was voluntary and that they were not obliged to provide answers to any question(s) with which they were uncomfortable.

The study was conducted from September through November 1998. Data were collected through a self-administered questionnaire, which were translated to Kiswahili, the national language. Filling of the questionnaire took place in classrooms and was supervised by the Principal investigators and two research assistants who were trained prior to fieldwork. The research assistants were teachers from schools not involved in the survey. The class teachers were not allowed to walk around in the classroom while participants were filling the questionnaires. Participants were allowed to ask questions if they had any problem during the process of filling the questionnaire and clarifications were given. The majority of the participants completed the questionnaire in about one hour. For the purpose of this paper, socio-demographic and health services utilisation information as explained below was sought.

Dependent variables: Two measures were used as dependent variables: use of modern health services and use of traditional health services within two years prior to the survey. These were measured by asking respondents whether or not they had sought modern or traditional health services, respectively, within two years prior to the survey (responses: "Yes several times", "yes once", "not at all"). Those who stated that they had sought modern or traditional health services, at least once, were categorised as having used modern and traditional health services, respectively.

Determinants: Three groups of variables (predisposing, enabling and need) were used as determinants.

Predisposing variables: Information regarding gender, age, and people with whom the respondents lived during the school term (living situation) was used as predisposing variables.

Enabling variables: Two proxy measures of family resources were used as enabling variables. One measure was based on responses to the question whether or not participants perceived poverty as a threat against their health (responses: "It is a very great threat", "It is a great threat", "It is quite a threat" "It is not a threat at all"). Another measure was based on reported possession of a Television, Video and Radio at home ("yes/no" responses). Information about possession of these items was used to construct an index for socio-economic status of the family. The responses were scored 0 if they did not possess an item and 1 if they did. A sum score ranging from $0-3$ and mean 1.8 was obtained, low scores reflecting having fewer items. Based on the scores respondents were grouped into two categories of socio-economic status: low (score 0 - 1) and high (score 2-3).

Need variable: Self-rated health status was used as need variable based on responses to the question "how healthy do you think you are?" (responses: "I am very healthy", "I am healthy", "I do not think I am healthy", "I don't know").

Other information sought included: type of health facility/ healer last visited, main reason(s) for the visit (chosen from a given list of symptoms, namely, fever, cough, diarrhoea, injury, 
abnormal genital discharge, seek condoms, seek contraceptives other than condoms, seek circumcision), whether or not participants felt free to explain the problem(s) they had to practitioners who attended them, whether or not the practitioners gave them sufficient time to explain their problems and whether or not participants were given sufficient information regarding the problem(s) they presented. Furthermore, participants were asked to indicate, overall, their level of satisfaction with the health services they received during the last visit from a five point scale ( $1=$ very satisfied, $5=$ very unsatisfied $)$.

The check-off symptoms list included common (fever, cough, injury) and rare (diarrhoea, genital discharge, need for condoms/contraceptives, need for circumcision), reasons for seeking health services among young people according to the Arusha regional hospital out-patient register. "Others (specify)" category was also included on the symptoms list in order to allow respondents to indicate any other reasons they had besides those listed.

Data analyses: The data were analysed using SPSS/PC+ version 9.0(15). Fisher's exact test was used to test differences between sub-groups of categorical variables when appropriate, otherwise the standard Chi-squared test was used. Assessment for linear trend was done using Chi-squared test for linear trend. Univariate logistic regression analysis was used as a first step to assess association between predictor variables and health services utilisation. Then multiple logistic regression analyses, controlling simultaneously for relevant predictors, were performed to assess the independent association of each predictor and outcomes of interest. Separate models were fitted for the use of modern and the use of traditional health services. Odds ratios (OR) with corresponding $95 \%$ confidence intervals $(\mathrm{CI})$ are reported.

\section{RESULTS}

Use of health services: Information regarding use of health services was available for 3359 of the 3603 respondents. Of these, $77 \%$ used modern health services only, $1.3 \%$ used traditional services only, $7.6 \%$ used both and $14 \%$, did not use any health service (Table 1 ). Respondents who were living alone or in a boarding school reported higher use of modern health services only than those who were living with guardians $\left(\chi^{2}{ }_{(1)}=9.5, p\right.$ $=0.01$ ). Use of both types of services increased with increase in the respondent's age ( $\chi 2$ trend $=6.7, \mathrm{df}=2, \mathrm{p}<$ 0.01 ); and was higher for respondents who did not think they were healthy or did not know their health status than those who said they were healthy or very healthy $\left(\chi 2_{(1)}=\right.$ 12.3, $\mathrm{p}=<0.01$ ) (Table 1).

Table 1

Use of health services within the past two years by socio-demographic and health variables

\begin{tabular}{|c|c|c|c|c|c|}
\hline Characteristic & $\begin{array}{r}\text { Total } \\
\text { number }\end{array}$ & $\begin{array}{r}\% \text { used } \\
\text { only modern }\end{array}$ & $\begin{array}{r}\% \text { used } \\
\text { only traditional }\end{array}$ & $\begin{array}{r}\% \text { used } \\
\text { both }\end{array}$ & $\begin{array}{l}\% \text { used } \\
\text { none }\end{array}$ \\
\hline \multicolumn{6}{|l|}{ Total series with valid } \\
\hline \multicolumn{6}{|l|}{ Gender } \\
\hline Male & 1742 & 76.3 & 1.4 & 8.0 & 14.3 \\
\hline Female & 1601 & 78.0 & 1.1 & 7.1 & 13.7 \\
\hline \multicolumn{6}{|l|}{ Age (yrs) } \\
\hline 15 or less & 648 & 77.6 & 1.2 & 6.2 & 15.0 \\
\hline $16-17$ & 1270 & 77.4 & 1.5 & 6.9 & 14.2 \\
\hline $18-19$ & 913 & 76.3 & 1.2 & 8.4 & 14.0 \\
\hline $20+$ & 513 & 76.9 & 1.2 & 9.7 & 12.2 \\
\hline \multicolumn{6}{|l|}{ School location } \\
\hline Urban & 1429 & 75.4 & 1.0 & 8.4 & 15.2 \\
\hline Semi-urban & 1153 & 79.2 & 1.4 & 6.0 & 13.4 \\
\hline Rural & 777 & 77.0 & 1.8 & 8.6 & 12.6 \\
\hline \multicolumn{6}{|l|}{ Living situation } \\
\hline Alone/boarding & 1212 & 79.7 & 1.4 & 7.8 & 11.1 \\
\hline One or both parents & 1713 & 76.3 & 1.2 & 7.2 & 15.3 \\
\hline Guardians & 381 & 72.2 & 0.8 & 9.7 & 17.3 \\
\hline \multicolumn{6}{|c|}{ Poverty threat against health } \\
\hline Great/very great threat & 1106 & 74.5 & 1.4 & 8.9 & 15.2 \\
\hline Quite a threat & 1511 & 78.2 & 1.7 & 7.7 & 12.4 \\
\hline No threat & 690 & 78.0 & 0.4 & 5.5 & 16.1 \\
\hline \multicolumn{6}{|l|}{ SES of family } \\
\hline High & 1558 & 79.2 & 1.2 & 6.8 & 12.8 \\
\hline Low & 1743 & 75.2 & 1.3 & 8.3 & 15.2 \\
\hline \multicolumn{6}{|l|}{ Self-rated health status } \\
\hline Very healthy/healthy & 3067 & 76.6 & 1.2 & 7.2 & 14.0 \\
\hline \multicolumn{6}{|l|}{ Don't think I am healthy/ } \\
\hline Don't know & 257 & 71.2 & 2.3 & 11.7 & 14.8 \\
\hline
\end{tabular}

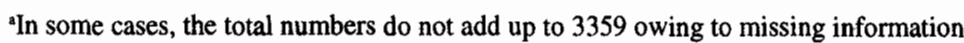

SES = Socio-economic status 
Table 2

A comparison of selected attributes of modern and traditional services

\begin{tabular}{|c|c|c|c|c|c|c|}
\hline \multirow[b]{2}{*}{ Variable } & \multicolumn{3}{|c|}{ Modern services } & \multicolumn{3}{|c|}{ Traditional services } \\
\hline & Total $^{a}$ & Male & Female & Total " & Male & Female \\
\hline Total series & 2844 & 1468 & 1363 & 300 & 164 & 132 \\
\hline \multicolumn{7}{|l|}{ Facility } \\
\hline Hospital & 62.6 & 58.4 & $67.2^{*}$ & & & \\
\hline Health centre & 6.9 & 7.2 & 6.5 & & & \\
\hline Dispensary & 30.5 & 34.4 & $26.3^{*}$ & & & \\
\hline \multicolumn{7}{|l|}{ Healer } \\
\hline Herbalist & & & & 52.7 & 57.7 & 46.6 \\
\hline Spiritual & & & & 27.9 & 16.2 & $42.2 *$ \\
\hline Circumcision practitioner & & & & 13.6 & 18.3 & $7.8^{* *}$ \\
\hline Other & & & & 5.8 & 7.8 & 3.4 \\
\hline \multicolumn{7}{|l|}{ Reason for use } \\
\hline Fever & 63.1 & 60.0 & $66.6^{*}$ & 41.5 & 34.2 & $51.1 * *$ \\
\hline Cough & 8.4 & 7.9 & 9.0 & 11.6 & 7.7 & $16.7^{* *}$ \\
\hline Injury & 9.4 & 11.1 & $7.5^{*}$ & 14.0 & 17.1 & 10.0 \\
\hline Diarrhoea & 1.8 & 2.7 & 0.9 & 5.8 & 6.8 & 4.4 \\
\hline Genital discharge & 0.8 & 0.5 & 1.1 & 2.9 & 3.4 & 2.2 \\
\hline Contraceptives/condoms & 1.0 & 1.0 & 1.1 & 1.4 & 1.7 & 1.1 \\
\hline Circumcision & 2.9 & 4.5 & $1.2^{*}$ & 8.2 & 12.8 & $2.2 *$ \\
\hline More than one reason & 0.3 & 0.1 & 0.4 & 14.5 & 16.2 & 12.2 \\
\hline Other & 12.2 & 12.2 & 12.2 & 0.0 & 0.0 & 0.0 \\
\hline \multicolumn{7}{|l|}{ Freedom of expression } \\
\hline Free & 94.2 & 95.1 & 93.3 & 81.3 & 83.1 & 79.0 \\
\hline Not free & 5.8 & 4.9 & 6.7 & 18.7 & 16.8 & 21.0 \\
\hline \multicolumn{7}{|l|}{ Time for expression } \\
\hline Sufficient & 92.2 & 91.0 & $93.4^{* *}$ & 80.4 & 81.2 & 79.4 \\
\hline Insufficient & 7.8 & 9.0 & 6.6 & 19.6 & 18.8 & 20.6 \\
\hline \multicolumn{7}{|l|}{ Information given } \\
\hline Adequate & 88.4 & 86.3 & $90.6^{*}$ & 73.6 & 73.9 & 73.1 \\
\hline Inadequate & 11.6 & 13.7 & 9.4 & 26.4 & 26.1 & 26.9 \\
\hline \multicolumn{7}{|l|}{ Overall satisfaction } \\
\hline Very satisfied & 51.2 & 51.9 & 50.4 & 36.1 & 35.5 & 36.8 \\
\hline Satisfied & 37.4 & 35.8 & 39.1 & 39.4 & 39.7 & 39.1 \\
\hline Neutral & 4.7 & 4.7 & 4.6 & 10.6 & 12.4 & 8.0 \\
\hline Unsatisfied & 5.4 & 5.7 & 5.0 & 10.1 & 7.4 & 13.8 \\
\hline Very unsatisfied & 1.4 & 1.8 & 0.9 & 3.8 & 5.0 & 2.3 \\
\hline
\end{tabular}

${ }^{a}$ The total number of males and females do not add up to 2844 for modern and 300 for traditional services owing to missing gender information for some; ${ }^{b}$ mainly fever and injury for modern and fever and cough for traditional health services, ${ }^{*} p<0.01$ and $* * p<0.05$ comparing gender within each type of service.

Of the modern health facilities visited last, hospital followed by dispensary were most frequently mentioned, whereas for the traditional healers visited last, herbalist followed by spiritual were most frequently mentioned (Table 2). A significantly higher proportion of females than males went to a hospital and a spiritual healer while the converse was true with regard to those who visited a dispensary and a traditional circumcision practitioner.

Although for both modern and traditional health services fever was the most common reason for seeking health care, there were relatively more complaints of fever with respect to modern than traditional services; while the converse was true for cough, injury, diarrhoea, genital discharge, need of circumcision and consultation for more than one health problem (Table 2). For both modern and traditional health services, females compared to males, suffered more from fever and needed less circumcision services. Of the respondents $h$ services, females suffered less from injury whereas of those who used traditional health services females suffered more from cough compared to males (Table 2). About 12\% of the respondents who used modern services specified other complaints than those on the check-off list as reasons for seeking care. These included headache, abdominal pain, dental ache, chest pain, skin rashes and need of medical check up.

The majority of respondents said they were free to explain their health problems to modern or traditional health practitioners who attended them during the last visit, had sufficient time for explaining the problems and they received adequate information about those problems. Also, the majority of the respondents were either satisfied or very satisfied, overall, with the services they received. However, freedom of expression, time for expression, amount of information given and overall satisfaction with the health services provided was notably higher for modern than traditional services (Table 2).

Overall, a higher proportion of females than males asserted that they had sufficient time to explain the problems 
Table 3

Factors associated with utilisation of health services in the previous two years

\begin{tabular}{|c|c|c|c|c|c|c|c|}
\hline \multirow[b]{2}{*}{ Variable } & \multirow[b]{2}{*}{ Group } & \multirow[b]{2}{*}{$\mathrm{N}(\%)$} & \multicolumn{2}{|c|}{ Used modern } & \multicolumn{3}{|c|}{ Used traditional } \\
\hline & & & $\begin{array}{r}\text { Crude } \\
\text { OR(95\% CI) }\end{array}$ & $\begin{array}{r}\text { Adjusted }^{b} \\
\text { OR }(95 \% \mathrm{CI})\end{array}$ & $N(\%)$ & $\begin{array}{r}\text { Crude } \\
\text { OR(95\% CI) }\end{array}$ & $\begin{array}{r}\text { Adjusted } \\
\text { OR }(95 \% \mathrm{Cl})\end{array}$ \\
\hline Total series with valid responses ${ }^{a}$ & 3359 & $2844(84.7)$ & & & $300(8.9)$ & & \\
\hline \multicolumn{8}{|c|}{ Gender } \\
\hline Male & 1742 & $1468(84.3)$ & 1.0 & 1.0 & $164(9.4)$ & 1.0 & 1.0 \\
\hline Female & 1601 & $1363(85.1)$ & $1.1(0.9-1.3)$ & $1.2(1.0-1.4)$ & $132(8.2)$ & $0.9(0.7-1.1)$ & $0.8(0.6-1.1)$ \\
\hline \multicolumn{8}{|l|}{ Age (yrs) } \\
\hline$<18$ & 1918 & $1614(84.2)$ & 1.0 & 1.0 & $155(8.1)$ & 1.0 & 1.0 \\
\hline $18+$ & 1428 & $1220(85.4)$ & $1.1(0.9-1.3)$ & $1.1(0.9-1.3)$ & $144(10.1)$ & $1.3(1.0-1.6)$ & $1.2(0.9-1.5)$ \\
\hline \multicolumn{8}{|l|}{ Living situation } \\
\hline Alone/boarding & 1212 & $1061(87.5)$ & 1.0 & 1.0 & $112(9.2)$ & 1.0 & 1.0 \\
\hline One or both parents & 1713 & $1430(83.5)$ & $0.7(0.6-0.9)$ & $0.7(0.6-0.9)$ & $144(8.4)$ & $0.9(0.7-1.2)$ & $0.8(0.6-1.0)$ \\
\hline Guardians & 381 & $312(81.9)$ & $0.6(0.5-0.9)$ & $0.6(0.4-0.9)$ & $40(10.5)$ & $1.1(0.8-1.7)$ & $0.8(0.6-1.3)$ \\
\hline \multicolumn{8}{|l|}{ Poverty threat against health } \\
\hline Great/very great threat & 1106 & $922(83.4)$ & 1.0 & 1.0 & $114(10.3)$ & 1.0 & 1.0 \\
\hline Quite a threat & 1511 & $1298(85.9)$ & $1.2(1.0-1.5)$ & $1.2(1.0-1.5)$ & $142(9.4)$ & $0.9(0.7-1.2)$ & $0.9(0.7-1.2)$ \\
\hline Not a threat & 690 & $576(83.5)$ & $1.0(0.8-1.3)$ & $1.0(0.8-1.3)$ & $41(5.9)$ & $0.6(0.4-0.8)$ & $0.6(0.4 \cdot 0.9)$ \\
\hline \multicolumn{8}{|l|}{ SES of family } \\
\hline High & 1558 & $1340(86.0)$ & 1.0 & 1.0 & $125(8.0)$ & 1.0 & 1.0 \\
\hline Low & 1456 & $1456(83.5)$ & $0.8(0.7-1.0)$ & $0.8(0.6-0.9)$ & $167(9.6)$ & $1.2(1.0-1.6)$ & $1.2(0.9-1.5)$ \\
\hline \multicolumn{8}{|l|}{ Self-related health status } \\
\hline $\begin{array}{l}\text { Very healthy/healthy } \\
\text { Don't think }\end{array}$ & 3067 & $2599(84.7)$ & 1.0 & 1.0 & $258(8.4)$ & 1.0 & 1.0 \\
\hline I am healthy / Don't know & 257 & $213(82.9)$ & $0.9(0.6-1.2)$ & $0.9(0.6-1.3)$ & $36(14.0)$ & $1.8(1.2-2.6)$ & $1.7(1.1-2.5)$ \\
\hline
\end{tabular}

${ }^{a}$ In some variables the total number do not add up to 3359 owing to missing information.

b Adjusted for gender, age, school location, living situation, poverty threat against health, SES of family and self-rated health status

$\mathrm{OR}=$ Odds ratio, $\mathrm{CI}=$ Confidence interval, $\mathrm{SES}=$ Socio-economic status

they had to modern health practitioners and were given adequate information about the health problems they had (Table 2). However, stratified analysis revealed that the gender difference in relation to time given for expressing problems existed at hospital level only whereas for information given the difference was apparent at hospital and dispensary levels. Of the 256 respondents who used both modern and traditional services, $40 \%$ had used the two types of services with similar complaints (mostly being fever) while for the remaining proportion the reasons differed.

Determinants of health services utilisation: Respondents who were living with parents and those who were living with guardians during the school term were less likely to use modern health services in the past two years than those living alone or boarders. Also, respondents who were categorised as belonging to families of low socio-economic status were significantly less likely to use modern health services than those belonging to families of higher socio-economic status (Table 3 ).

An age by gender interaction was found in relation to utilisation of modern health services such that, gender was associated with the use of health services in older but not in younger respondents. Specifically, females who were aged 18 years or more were more likely to use modern health services than their male counterparts $(O R=1.6$, $95 \% \mathrm{CI}=1.1$ to 2.3 ).

Respondents who perceived poverty as not being a threat against their health were significantly less likely to utilise traditional health services than those who perceived it to be a great or very great threat. Respondents who did not think they were healthy or did not know of their health status were significantly more likely to use traditional health services than those who perceived themselves as being very healthy or healthy (Table 3 ). Respondents who were aged 18 years and above compared to those aged less than 18 years and respondents who were categorised as belonging to families of low socio-economic status compared to those of high socio-economic status, had increased tendency to use traditional health services, although the associations were not statistically significant (Table 3).

\section{DISCUSSION}

The study revealed that the vast majority of secondary school students used modern health services whereas a low proportion had used traditional services during the past two years. The level and general pattern of health services utilisation found in this study conform to that reported for primary school pupils in the Arusha urban district(5). However, there are a few exceptions. Whereas the study among primary school pupils did not find any gender difference with respect to a visit to hospital and a spiritual healer, time allowed for expressing health problems and information provided by the modern health practitioners, in the present study a gender difference was found. Specifically, more females than males utilised hospital services and spiritual healers. Also, more females 
than males reported having had sufficient time to express their problems to clinicians who attended them at the hospital and having received adequate information from the clinicians at hospital and dispensary levels, regarding the health problems they had.

In Tanzania, health centres and dispensaries are manned mainly by paramedics with 2-3 years of clinical training (with exception of a few privately owned ones which may have doctors) and offer non-specialised services with little capacity for ancillary investigations. Hospitals, on the other hand, have doctors and specialists in various disciplines, in addition to paramedics; and are better equipped with laboratory facilities. Our data show that, reasons categorised as "other", which included abdominal pain, ranked second in frequency among those who sought modern health services for both sexes. Abdominal pain in females may be associated with menstrual and other gynaecological disorders, which necessitate the attention of a doctor and a need for laboratory investigation. Thus, this might explain the observed gender difference in using hospital services. Research among adults elsewhere has shown that women utilise diagnostic health services more than men(16).

The finding that fever was the predominant reason for seeking modern as well as traditional health care was expected. Most of the fevers might have been due to malaria, since this is one of the main manifestations of this disease. Nationwide and for the Arusha region, malaria is the number one cause of outpatient attendance and inpatient admission for all ages $(1)$

Consistent with the findings by previously work in Tanzania(5,17-19), the overall use of traditional health services reported in this study was low. Moreover, the results indicate that respondents had less freedom of expression, time for expression, amount of information given and overall satisfaction with the health services provided in relation to consultations with traditional than modern practitioners. It is possible that respondents may have under-reported the use of traditional health care system since one of the persons who collected the data was associated with modern health system. However, given the fact that the questionnaire was anonymous and the similarity of our findings to those of other reported work in the country, we do not think that under-reporting could have significantly affected the results. Thus, in view of these results one might question the usefulness of policies advocating strengthening traditional health services as part of the integrated health care delivery system. It seems that, strengthening the modern health system could be of more benefit to this population of young people. However, studies in other parts of Africa have shown that traditional health care practitioners can play an important role in the treatment, prevention and control of spread of illness and disease as well as promoting health(20-23).

Our findings show that respondents who were living with parents or guardians during the school term were significantly less likely to utilise modern health services than those who were living alone or boarders. Assuming that the reported use of health services occurred during the school term (ten months in a year); then possibly respondents who were living with some family members might have, most of the time, used home-kept drugs or drugs directly bought from shops instead of going to a health care facility whenever they felt ill. Thus, this might account for the observed difference. This argument may be supported by the fact that, of the reasons for seeking modern health care; fever followed by conditions defined as "other" (including headache, abdominal pain and skin rashes) ranked high. Drugs for alleviation of these symptoms are normally available in drug shops and some of them may be procured without prescriptions. Therefore, self-treatment can easily be practised for these health conditions. Indeed, one study in Tanzania found that $72 \%$ of the respondents had treated themselves with home-kept antimalarial drugs for a suspected malarial fever before seeking treatment from health facilities(24). Self-treatment for malaria and other illnesses is also common elsewhere in Africa(25-27). In the wake of the cost-sharing policy for health services in Tanzania, the practice of self-medication is likely to increase.

In this study, an interaction between age and gender with respect to overall use of modern health services was found, such that older females reported higher use than their male counterparts. These results are consistent with those of researchers in other countries $(11,28)$. However, Settertobulte and colleagues demonstrated that this observation was truc only for some types of illnesses; after removing gender-specific reasons, such as menstruation, from the analysis(28). Therefore, further exploration of gender-related factors is important if we are to fully understand the reasons why young people utilise modern health services. Such knowledge could help in designing health care delivery systems that are attractive to young people of different sexes and various age groups.

In Tanzania, the cost-sharing policy for modern health services allows for exemption from paying for certain groups and waiver system for those who are unable to pay for the services in government-owned health facilities, so as to ensure equity in access to health care(2). Moreover, up to now user fees have not been introduced for health services delivered by government-owned health centres and dispensaries. However, still we found that respondents who were categorised as belonging to families of low socio-economic status were less likely to use modern health services than those who were categorised as belonging to families of high socio-economic status. This observation may be explained as follows. First, respondents who belonged to families of low socio-economic status were less likely to utilise modern health services presumably because they could not afford to pay for the services. If so, then there is cause for concern as this connotes existence of a discrepancy between the costsharing policy and its implementation. It is tempting to think that in some areas of the country, such as the one studied, the waiver system might not be adhered to. Indeed, an evaluation study by the Ministry of Health 
found that some government health facilities were invariably charging all patients for health services without paying attention to the exemption and waiver guidelines(2).

An alternative explanation might be that, since the government-owned health facilities are known to have shortages of drugs and other essential equipment(29,30), most students might have been obliged to seek health care from private facilities where charges for services are higher and there is no exemption or waiver system. This might pose a formidable challenge to health services utilisation by students from poor families. Other researchers have also reported low utilisation rate of modern health services by poor people $(9,12,26,31,32)$. From the data, however, ownership of the health facilities from which our respondents sought care can not be ascertained. This information was not asked for, because we did not expect the respondents to have accurate knowledge of it. Therefore, further work is required to identify barriers to utilisation of modern health services by students from poor families.

Self-rated health status has consistently been found as an important predictor of use of modern health services; that is, the poorer the health the higher the use of health services $(8,9,14)$. In our study this association was not found.

Respondents who perceived poverty as being a very great threat against their health were more likely to utilise traditional health services than those who perceived it not to be a threat against their health. Further, those who were categorised as belonging to families of low socio-economic status had increased tendency to use traditional health services than those from families of high socio-economic status. This might imply that poor families are more likely to seek health care from the traditional system, possibly due to perceived low cost for the services. However, it should also be noted that, even among, respondents from poor families, the great majority had used modern health services during the two years period.

Self-rated health status was associated with use of traditional health services. Respondents who reported that they did not think they were healthy or did not know of their health status were significantly more likely to use traditional health services than those reporting being very healthy or healthy. This is consistent with the findings from Ghana(14).

Similar to the findings by Fosu in Ghana(14), gender and age were not significantly associated with utilisation of traditional health services. However, there was a tendency for utilisation of traditional health services to increase with increase in the respondent's age. The reason for this trend is unclear.

Two limitations for our study deserve comment. First, the study is limited to school going population. In Tanzania, secondary school students represent less than a fifth of all primary school levers. It is likely that out-of school young people have different health care needs and use pattern. Thus, our results probably do not adequately reflect the use of health services and its determinants for all young people.
Secondly, there could be a bias in recalling the visits to the health facilities and traditional healers, reasons for those visits and satisfaction with the services provided, given the long recall period. A two-week recall period in combination with the use of symptom check-list including "tracer conditions" has been recommended in health interview surveys in developing countries when measuring illness and visits to health care facilities, in order to minimise recall bias(33). Moreover, it has been argued that ratings of satisfaction that are made later than six weeks after an encounter with a physician assess a generalised perception of satisfaction rather than the patients' specific satisfaction with the encounter(34). We were unable to independently verify each respondent's reported use of health services because information was not collected on name and location of the facilities from where respondents received the services. Further, when asking about type of health care facility/healer visited, reasons for the visit, and satisfaction with the health services provided, the recall period was not given priority, since we were interested in events related to the last visit. The time when the last visit occurred was, however, not determined; and therefore, it is difficult to ascertain how recall bias may have affected the results in these respects.

In conclusion, the majority of secondary school students utilise modern health services and a small proportion use traditional health services. Further, satisfaction with traditional health care system was lower than for modern health services. These results point to the need for further research to elucidate the factors that facilitate or impede use of health services by young people in Tanzania, and also for reviewing policies advocating strengthening of traditional health care system as part of integrated health care delivery system. Improvement of the modern health care system is more likely to be of benefit to secondary school students.

\section{ACKNOWLEDGEMENTS}

The first author is a fellow supported by the Norwegian State Educationa Loan Fund. The Norwegian council of Universities' programme for Development Research and Education (NUFU) supported this work The efforts of our research assistants are acknowledged and appreciated.

\section{REFERENCES}

1. Ministry of Health. Health statistics abstract 1997, Dar es Salaam, Tanzania.

2. Ministry of Health. Implementation of health services user fees in Tanzania: An evaluation of progress and potential impact 1996, Dar es Salaam, Tanzania.

3. Swantz M-L. Manipulation of multiple health systems in the coastal regions of Tanzania. In: Jacobson-Widding A, Westerlund D (eds). Culture, Experience and Pluralism: Essays on African Ideas of illness and Healing, Uppsala, Almqvist and Wiksell; 1989: 277-287.

4. Bureau of Statistics: Tanzania Demographic and Health Survey, 1996: Planning Commission, Dar es Salaam, Tanzania; and Macro International Inc. Calverton, Mary Land, 1997.

5. Masatu M.C., Klepp K-I. and Kvåle G. Use of health services and reported satisfaction among primary school adolescents in Arusha, Tanzania. J. Adolesc. Hlth. 2001; 278-287. 
6. Aday L.A. and Andersen R. A framework for the study of access to medical care. Hith Serv. Res 1974; 9: 208-20.

7. Briscoe M.E. Why do people go to the doctor'? Sex differences in the correlates of GP consultation. Soc. Sci. Med. 1987; 25: 507513.

8. Fylkesnes K. Determinants of health care utilisation - visits and referrals. Scand. J. Soc. Med. 1993; 21: 40-50.

9. Gilbert G.H., Duncan R.P. and Vogel W.R. Determinants of dental care use in dentate adults: Six-monthly use during a 24-month period in the Florida dental care study. Soc. Sci. Med. 1998; 47: $727-737$.

10. Ntabaye M. K., Scheutz F. and Poulsen S. Household survey of access to and utilisation of emergency oral health care services in rural Tanzania. East Afr. Med. J. 1998; 75:649-653.

11. Ryan S.A., Millstein S.G., Greene B. and Irwin C.E. Utilisation of ambulatory health services by urban adolescents. J. Adolesc. Hlth. 1990; 18:192-202.

12. Fosu GB. Childhood morbidity and health services utilisation: Cross-national comparisons of user- related factors from DHS data. Soc. Sci. Med. 1994; 38:1209-1220.

13. Subedi J. Modern Health Services and Health Care Behaviour: A survey in Kathmandu, Nepal. J. Hlth. Soc. Behav. 1989; 30: 412-420.

14. Fosu, GB. Access to Health care in Urban Areas of Developing Societies. J. Hlth. Soc. Behav. 1989; 30:389-411 .

15. Norusis M.J. SPSS for Windows, Version 9.0. SPSS Inc, Chicago, Illinois, USA; 1998.

16. Bertakis K.D., Azari R., Helms L.J., Callahan E.J. and Robbins $J$.A. Gender differences in the utilisation of health care services. $J$. Fam. Pract. 2000; 49:147-152.

17. Sarita P.T.N. and Tuolllinen R. Use of health services in two rural communities in Tanzania. Commun. Dent. Oral. Epidem. 1993; 21:133-135.

18. Wyss K., Whiting D., Kilima P., McLarty D.G., Mtasiwa D. and Tanller M. et al. Utilisation of government and private health services in Dar es Salaam. East Afr. Med. J. 1996; 73:357-363.

19. Ministry of Health. Policy implications of Adult Morbidity and Mortality: End of Phase 1 Report 1997, Dar es Salaam, Tanzania.

20. Shai-Mahoko S.N. Indigenous Healers in the North West province: A survey of their clinical activities in health care in the rural areas. Curationis. 1996; 19:31-34.
21. NdubaniP. and Hojer B. Traditional healers as source of information and advice for people with sexually transmitted diseases in rural Zambia. Trop. Doct. 1999; 29:36-38.

22. Hoff $W$. Traditional health practitioners as primary health care workers. Trop. Doct. 1997; 27 (suppl 1): 52-55.

23. Green E.C. The participation of African traditional healers in AIDS/STD prevention programmes. Trop. Doct. 1997; 27 (suppl 1): 56-59.

24. Mnyika K.S., Killewo J.Z.J. and Kabalimu T.K. Self-medication with antimalarial drugs in Dar es Salaam, Tanzania. Trop. geogr. Med. $1995 ;$ 47:32-34.

25. Mwenesi H., Harpham T. and Snow R.W. Child malaria treatment practices among mothers in Kenya. Soc. Sci. Med. 1995; 40:12711277.

26. Develay A., Sauerborn R. and Diesfeld H.J. Utilisation of health care in an African Urban area: Results from a household survey in Ougadougou, Burkina-Faso. Soc. Sci. Med. 1996; 43:1611-1619.

27. Ndyomugyenyi, R., Neema S. and Magnussen P. The use of formal and informal services for antenatal care and malaria treatment in rural Uganda. Hlth Pol. Plan. 1998; 13:94-102.

28. SettertobulteW. and Kolip,P. Gender-specific factors in utilisation of medical services during adolescence. J. Adolesc. 1997; 20: 121 132.

29. Kanji N., Kilima P., Lorenz N. and Garner P. Quality of primary outpatient services in Dar es Salaam: a comparison of government and voluntary providers. Hlth Pol. Plan. 1995; 10:186- 190.

30. Ahmed A.M., Urassa D.P., Gherardi E. and Game N.Y. Patients' perception of public, voluntary and private dispensaries in rural areas of Tanzania. East Afr. Med. J. 1996; 73:370-374.

31. Makinen M., Waters H., Rauch M., Almagambetova N., Bitran R. and Gilson L. et al. Inequalities in health care use and expenditures: empirical data from eight developing countries and countries in transition. Bull. Wld. Hlth. Organ. 2000; 78:55-65.

32. Castro-Leal F., Dayton J., Demery L. and Mehra K. Public spending on health care in Africa: do the poor benefit? Bull Wld. Hlth. Organ. $2000 ; 78: 66-74$.

33. Kroeger A. Response errors and other problems of health interview surveys in developing countries. Wld. Hlth. Statist. Quart. 1985; 38:15-37.

34. Lochman, J.E. Factors related to patients' satisfaction with their medical care. J. Commn. Hlth. 1983; 9:91-109. 